\title{
Examining the Roles of Traditional Guidance and Counselling Among the People of Sefwi- Bekwai in the Western- North Region of Ghana, Africa
}

\author{
Rabbi Darko, Joseph Asamoah - Gyawu, Gilbert Konwie Langu \\ Knust Counselling Center, Kwame Nkurmah University of Science and Technology, Kumasi, Ghana
}

\begin{abstract}
The study examined the roles of traditional guidance and counselling among the people of Sefwi-Bekwai in the Western-North Region of Ghana, Africa. The study followed a qualitative case study design utilizing interviews to collect data. Using purposive sampling, data was collected from four natives of Sefwi-Bekwai who have lived in the traditional area for more than 50 years and are well respected. Inductive thematic analysis was used to analyse the data. The study revealed that taboos, folktales and traditional music are some of the tools used in practicing traditional guidance and counselling in Sefwi-Bekwai. The study also discovered that occasions like marriage ceremonies, funeral, puberty, during unwanted pregnancies and travelling are some of the precipitating factors that trigger guidance and counselling. The study recommends that there should be training courses in counselling for traditional leaders. Such training can assist these counsellors to beef up their counselling services delivery. Furthermore, the study recommends that to maintain the African philosophy, the people need to go back to their roots to reclaim from their past practices that are wholesome and best, merge it with best western practices and use it to rebuild African guidance and counselling with modernity. This would enable them to render a more satisfying and effective assistance to their clients.
\end{abstract}

Keywords: Traditional guidance and counselling and SefwiBekwai.

\section{INTRODUCTION}

$\mathrm{T}$ he World Health Organisation $(2006 ; 1)$ states that the practice of counselling entails the application of 'mental health, psychological or human development principles through cognitive, affective, behavioural or systematic intervention strategies.' This implies that counselling is a specialized service that provides clients with a supportive, non-judgmental and confidential environment in which they can explore any emotional, psychological or personal problems that they may be encountering.

Guidance can be defined as a process, developmental in nature, by which an individual is assisted to understand, accept and use his/her abilities, aptitudes and interests and attitudinal patterns in relation to his/her aspirations. Guidance can also be looked at as a programme or services to individuals based upon the need of each individual, an understanding of his/her immediate environment, the influence of environmental factors on the individual and the unique features of each school (Odebunmi 1992). Guidance is designed to help each individual adjust to his/her environment, develop the ability to set realistic goals for $\mathrm{him} /$ herself, and improve his/her education.

There seems to be nothing new about Guidance and Counselling services, because from time immemorial, many people, particularly the uninitiated such as parents, teachers, principals, educational administrators, soothsayers, clergy, elders etc. have been rendering this service. Traditional Guidance and Counselling can also be known as informal type of help. Achebe (1988) confirms this when he said that members of the society such as friends, members of extended family, chiefs, community elders, and members of one's age group have traditionally provided an informal type of help one way or the other when called upon. Systematic method of helping people has long been in existence in Ghana, although this has been disrupted by the advent of Western Education and Christianity. Egbochuku (2008) warned that Guidance and Counselling as a delivery service should not be misconstrued for the traditional type that is based on the principles of 'to guide, to direct on a course, to enlighten, or to assist', which was principally carried out in African setting by heads of families, Priests, and Church Leaders.

Counselling is, therefore, commonly referred to as 'talk therapy'. In the case of people in our local communities, counselling should enable them to appreciate their challenges and help them decide to have a more positive outlook towards life and carry on living by disregarding any deviant acts or behaviours. Traditional counselling methods have emphasized the importance of helping the individual, thus going against the influence of the family and community structures. Knowing when and how to integrate the family and community into counselling practice will empower culturally different clients and help them seek a collective solution rather than an individual one. Ghanaians have different cultural and historical background as compared to Western countries, hence using Western approaches to Guidance and Counselling in the Ghanaian context will not earn the required influence. Fortunately for us, guidance and counselling has since been with us especially among the Akans.

Counselling is by its very nature diverse in the context of a multicultural society, this implies that there are no ideal therapeutic approaches. Fortes and Evans-Pritchard (1987) maintained that in the traditional Akan political system there are series of hierarchical levels of authority which operate 
from the family units through the lineage until the final authority, the Omanhene or paramount chief, and in the case of Ashanti, the Asantehene. Considerably autonomy is recognised at every level, but with well-laid procedures for linkage at higher, more powerful points. Thus cases and guidance and counselling usually move steadily from the household, through the society and eventually to the highest authority, the King, if the need arises. These levels within the Akan context ensure the maintaining of law and social control among their members.

Traditional Counsellors do well to teach indigenes from early childhood to internalize the norms and values of the society to distinguish between right and wrong so as to pursue the one and avoid the other, and when after this they still go against the accepted ways of behaviour, some form of coercion is applied to make them conform. Despite the elaborate system of socialization found in the traditional societies in Ghana, there is no society in which breaches of accepted behaviour are not found. There are always people who do not do what is expected of them. Others do what they are not expected to do. If such people are allowed to pursue their deviant behaviour with impunity, there will be chaos in the society. This is one of the reasons traditional guidance and counselling has gained root in our traditional settings to help deal with this menace (Nukunya 2003).

\section{Objectives}

1. To determine the theoretical underpinnings of traditional guidance and counselling among the people of Sefwi-Bekwai.

2. To determine the constituents of guidance and counselling among the people of Sefwi-Bekwai in the Western-North of Ghana

3. To determine the tools for practicing Guidance and Counselling among the people of Sefwi-Bekwai in the Western-North of Ghana

4. To determine the role of traditional guidance and counselling among the people of Sefwi-Bekwai in Western-North of Ghana.

\section{Research Questions}

1. What are the theoretical underpinnings of traditional guidance and counselling among the people of SefwiBekwai?

2. What are the constituents of guidance and counselling among the people of Sefwi-Bekwai in the WesternNorth of Ghana?

3. What are the tools for practicing Guidance and Counselling among the people of Sefwi-Bekwai in the Western-North of Ghana?

4. What are the roles of traditional guidance and counselling among the people of Sefwi-Bekwai in Western-North of Ghana?

\section{The History and People of Sefwi-Bekwai}

In the extreme north of the Western Region of Ghana are three traditional states collectively known as Sefwi-Bekwai is made up of three mutually independent paramount states of Anhwlaso, Bekwai and Wiawso. It is bounded on the northeast by Ashanti (Asante), on the east by Denkyira and WassaAmanfi, on the south by Awowlo and on the west by the AnyiBaule of the Ivory Coast. It also shares a common boundary with Brong Ahafo in the north. All the three states share a common dialect Sefwi but almost all the people speak Twi (Akan). In addition, they have a common tutelary deity, Sobore, and a common annual yam festival - the Allelolle. (Hoitsbaum, 1925; Daaku,1970)

Since the middle of the Seventeenth century this vast stretch of territory has served as a centre of refuge for people escaping from the political centralization policies of their neighbours to the north and east. Refugees from BonoTakyiman, Wenchi, Adanse, Denkyira, Assin and Asante found ready welcome in this territory. It appears that the Awowlo rulers who formerly controlled modern Sefwi territory adopted an open door policy as a measure to increase the population of their state. Its virgin forest serves as bait for cocoa farmers and timber merchants from all over Ghana (Daaku 1970).

Traditional Guidance and Counselling is evident among the Akans precisely the people of Sefwi-Bekwai in the Western Region of Ghana. Logie (2009), the Akan people are a linguist group whose roots can mainly be found in Southern Ghana, the Ivory Coast to the West and Togo to the East in West Africa. They are the largest ethnic group in Ghana with approximately four million Akans living the areas mentioned above. According to the 2000, national population census, $49.1 \%$ of the Ghanaian population is Akans and about $44 \%$ of the population speak Akan as non-native speakers. The Akans history as a people can be traced back to the $13^{\text {th }}$ century where it is believed that they migrated from the North to occupy the whole of Southern Ghana. Akan is spoken as a native language in six of the ten regions in Ghana namely, Ashanti, Eastern, Western, Central, and Brong Ahafo Region. The Akans are made up of various dialects that are mutually intelligible. Sefwi Bekwai is a town that have greater respect for tradition as well as respect for authority.

The people of Sefwi Bekwai are religious and superstitious. They believe that religion represents a unified system of beliefs and practices relative to sacred things. They believe in the Supreme Being, smaller gods, witchcraft, divination, festival etc. According to the people of Sefwi Bekwai, it is even possible to learn directly from Spirit, through libation.The Akan people have a rich and diverse culture in which mythology plays an important role, the most famous of these are the Ananse or 'spider stories'. In Ghana, Ananse is a culture hero whose stories revolve around a spirit-spider who acts on behalf of 'Onyame'. Amongst other duties, he is the bringer of rain and fire and he is able to change his appearance 
at will, from spider to human or a combination of both, whichever is most appropriate, for the delivery of his message from 'Onyame' (Logie 2009)

\section{Definition of Terms}

- Guidance: according to Steward (1970) guidance is the assistance given to individuals in making intelligent choices and adjustments in their lives.

- Counselling: is the process of helping relatively normal individuals develop, make decisions and solve their problems (Bedu-Addo, 2000)

- Traditional Society: is a society characterised by the type of domination based on the belief in the legitimacy of an authority that has always existed (Nukunya 2003).

- Tradition is commonly regarded to be the basis of any traditional society; it is this characteristic which differentiates traditional society from all other society (Keulder 1997).

- Ethnic Group: is a socially defined category of people who identify with each other based on a shared social experience or ancestry (People, James and Bailey (2010).

\section{METHODOLOGY}

The research employed the qualitative case study design, a naturalistic inquiry procedure, to help define the experiences of the Akan people using the traditional theories in guidance and counselling vis-à-vis strategies meeting global modern practices. Qualitative research helps in a descriptive and exploratory analysis of people, actions, beliefs, perceptions and events

\section{Sampling}

Four traditional leaders were sampled for this study as key informants. These traditional leaders were indigenes of SefwiBekwai who have lived there for more than 50 years. The sampled participants were selected because they were regarded as "the wise" and rich in information about their respective societies. The other used selection criterion was their offering of traditional guidance and counselling to natives. Purposive sampling was used in the selection of participants for this study. Purposive sampling technique was used because the participants had rich information due to their accumulated experience in practicing guidance and counselling in Sefwi-Bekwai traditional area. Standard data collection procedures were followed such as: confidentiality, consent seeking and explaining focus of the study and many other relevant issues for many other relevant ethical considerations.

\section{Instrument}

Semi-structured interview guide was relied on to elicit information from the purposively sampled participants. Semistructured interview schedule offered participants the opportunity to construct their own world through relating their guidance and counselling experiences. Since the interviewers were working in the interpretive-qualitative framework, they were present with all their convictions and understandings interacting with participants in their socio-cultural context. For this reason, the interviewers personally conducted the one-on-one interviews; and that provided them with the opportunity to clarify issues that the participants raised about some questions in the instrument. The collected data were tape recorded after seeking audio taping consent from the participants and noted and observed field notes were also taken in case of recorder malfunction. The notes were written against the corresponding data as it was collected to minimize a labored data analysis.

\section{Data analysis}

All data collected through the interview schedules were analyzed qualitatively through the inductive thematic data analysis approach. The generated data was revised several times and the recorded audio-tapes were replayed to organize and establish the meaningfulness of the collected data to the study. This equally helped to identify the consistencies and differences in the collected data. Data was then transcribed, analyzed and interpreted.

Emerging patterns and themes from the collected data and supporting verbatim collections were presented under each section. Coding assisted in placing the collected data accordingly and this made data organization a much easier task. Furthermore, coding was successfully done identifying text segments and circling them, and assigning a code that precisely described the meaning of the text segment after which related codes were aggregated under each of the dominant themes identified. These were:

a. Theoretical underpinnings of traditional guidance and counselling.

b. Constituents of Traditional Guidance and Counselling

c. Tools for practicing Guidance and Counselling

d. Role of Traditional Guidance and Counselling

e. Situations that Precipitate the Offering of Traditional Guidance and Counselling

f. Traditional Practitioners of Guidance and Counselling and Formal Training

g. What are the Pros and Cons of Traditional Guidance and Counselling?

In attributing quotations to the interviewees, the participants were anonymously identified as Respondent 1 , Respondent 2 , Respondent 3 and Respondent 4 for their protection and ethical reasons. The organized data was continually revised to analyze and establish linkages and relationships with the rest of the collected data and a position was set taking all this into cognizance.

\section{RESULTS AND DISCUSSION}

Theoretical underpinnings of traditional guidance and counselling 
In the traditional settings there are no specific theoretical perspectives, however, there are beliefs and hearsays that has been with the people from generation to generation. Most of their traditions are orally transmitted.

According to Agyekum (2004), there is face ('anim') theoretical framework in the Akan settings which has some link with traditional Guidance and Counselling. The present work will adopt Agyekum's face theory in analysing the study. The face theory is indicated below:

Among the Akan, the etiquette norms are unwritten but form the tools of socialisation through which the upbringing of new members of Akan society (children and strangers) is achieved. They are well-established, so that in any social interaction people are able to distinguish between polite and impolite behaviour. According to the Akan cultural notion of face and its norms, the body part 'anim' plays an important role in communicative interaction. It is used symbolically as a reference point in communication. In every discourse, all participants must try as much as possible to respect the face of the other(s) as well as their own and also co-operate to maintain the face of each other.

The existence of face in interaction may affect the diction, into national patterns, style of speech, the choice of the appropriate register, and even the syntactic structure of the utterances in communication. He added that, a child who constantly breaks into adult conversation is reprimanded and scolded. The reprimand or scolding helps the child to deal with his or her problem of poking his/her nose into adult's affairs. It is a taboo for a child to insult an elderly person. Within the family, if an elderly person offends a younger one the socio-cultural norms do not allow the elderly to apologise. However, a small communicative mistake on the part of the younger against the adult is considered offensive and the child would have to apologise.

Agyekum explains that in the traditional settings there are respect for all persons and this is due to the fact that they belief every individual in made up of full potentials to love and to despise, to respect and to disrespect. R1, when asked whether there were any theoretical perspective governing traditional Guidance and Counselling revealed that there wasn't any, however when a problem evolved they found ways of dealing with it.

"there isn't any specific theory that guides the service rather they believe that everybody has strengths and weaknesses, so the traditional guidance and counsellors focus on the development of the individual strengths and downplays his weakness. "Asemba a,nipanaeka" so definitely problems may arise and when problems come they find ways and means to deal with them. (R1)

Respondent 2 (R2), also made a comment that confirmed the assertion of respondent 1 . Below are R2 comments:
"I don't know any theoretical perspectives but one thing I know is that we try to guide the individual to be polite and useful to his immediate family and all of us in Bekwai. We believe that if the individual is not guided and counselled he can be a threat to all of us and not to his family only. When one becomes an armed robber, he or she doesn't rob his family only but to anybody he/she chanced on, hence the responsibility lies on all of us to guide and counsel our people" (R2)

\section{Constituents of Traditional Guidance and Counselling}

Traditionally, a boy or girl is seen completely ignorant of certain actions and behaviours such as sexual matters, disrespecting adults etc therefore certain provisions are usually made to ensure that these young ones do not fall victims to these unscrupulous behaviours. Advice giving, prophecies, prescriptions, motivations and reward and punishments are some of the ingredients that constituent guidance and counselling in Sefwi Bekwai. Advice is usually given to the youth on daily basis. This is of the reason that, the youth are the most vulnerable in the society therefore advice giving is necessary to help them be on track. This is what respondent three (R3) said on advice delivery:

"For me, I give advice to my children always. Normally I do that at dawn because during that time I believe their minds are relax and calm to absorb everything I say to them. When they go to school, I am not there, when they are playing with their friends I will be at home so I wouldn't know what these people will feed them with. It is then my duty to find out what they were fed and when I realize they are bad, I try to help them erase that evil chaff and re-feed them with moral and biblical information" (R3)

In the Akan traditional settings, past, present and future events are capable of influencing one's behaviour. People who are able to tell them past and future events are given much reverence and are called Akomfo (Fortune-tellers). In the case of Sefwi Bekwai, it is the Akomfo and the spiritualists that give these prophecies. These prophecies are seen to be directions from the Supreme Being or the gods. The Akomfo and the Spiritualists are usually consulted in seeking for guidance and counselling.

Punishment and Reward is one of the commonest systems used in traditional guidance and counselling. In the Akan ethnic group, juvenile immorality, abuses, insults and other unscrupulous actions are severely punished. For instance, words like 'foolish', 'silly' and 'stupid' should wherever and whenever, possible never be used by people openly. Again, references to someone's parents or other relatives may also be offensive. Children who normally engage in these acts are severely punished and rebuked. In the case of Sefwi Bekwai, every adult is a parent and has the right to punish any child whether the child is his son or not. They believe that each and 
every adult has the responsibility to train a child to become productive. My last respondent (R4) said something on punishment.

\section{"Before a child is punished, he or she is made to realize his or her mistake, normally the child is sent to a private place where he or she is counselled. After thorough interrogation, the child will definitely realize his mistakes and he or she is made to apologise to the one he or she has offended. It is after the rendering of apology where the punishment comes". (R4)}

Reward on the other hand helps to reinforce good behaviour among children in the Akan settings. When the people are rewarded after exhibiting good moral behaviours, they are motivated to repeat that action several times which eventually forms part of their behaviour. Among the Akans, reward is usually given orally. "w'ayeadee, Onyamenhyirawo" (you have done well, May God bless you) is often used to motivate people to repeat a desired behaviour in the society. Reward can also be seen in several forms such as money giving, giving of gifts such as crate of eggs, inviting one for supper etc.

Prescriptions from the herbalist (Odunsini) also constitute traditional guidance and counselling in the Akan context. Herbalist often prescribes the appropriate medicine for some diseases. They are believed to have a second eye to look into the spirit and bring out certain required herbs for some specific diseases. The herbalist usually does not charge after prescription and always give guidance to how the herbs should be used and preserved. People who do not take the guidance from the herbalist normally find problems for themselves and some even die.

\section{Tools for practicing Guidance and Counselling}

Akan traditional counsellors employ varieties of tools in delivering guidance and counselling services. Some of the tools used are taboos, folktales, folksongs, proverbs, norms etc.

\section{Taboos}

The Akans have some form of relationship with the supernatural. They have strong belief for supernatural beings and believe that those beings have profound influence on the lives of people. It is said that in the past the penalty for a breach of taboo could be death or banishment. The adverse consequences of breaking a taboo may fall on the whole society. It is sufficient for one to commit fornication with a girl under the age of puberty and there is bound to be famine in the community, unless something is done ritually to cleanse the community of the abomination (Sarpong, 1974). It is therefore a matter of great concern for every member of the society to make sure that the more serious taboos are scrupulously observed. The object of taboo differs from society to society (Sarpong, 1974).
In the case of Sefwi Bekwai, breach of taboos is no longer punishable by death or banishment but rather the culprit is asked to pay a fine, buy a goat or sheep. These taboos are available to deter members of the ethnic group from doing what is inhuman or evil. Some of the taboos in Sefwi Bekwai are: no member of the land goes to farm on Thursdays, seeing the nakedness of women, sex in the bush, sleeping with another man's wife, abusive words towards the chief, sexual intercourse with a woman in her menstruation period, etc. The penalties stated above are in meted on culprits to save as deterrent to others. Respondent three (R3) had this to say on taboo:

"Here in Sefwi Bekwai, taboos shape our lives. No
one wants to fall victim of any of the taboos here
because the amount of money you will pay, you will
never forget in your life. Sometimes people who are
caught going contrary to any of the taboos are
disgraced and humiliated. For example, if one
engages in sexual intercourse with a woman in her
period or a woman who is impregnated by another
man, that person is openly disgraced, fined and most
often the issue is reported to the police. Again, having
sex with a family member is another serious taboo in
Sefwi Bekwai, such act is not countenanced and
victims of this crime pays huge sum of money for
rituals and at times handed to the police". (R3)

\section{Folktales}

Akan folktales are performed only at night and are performed before crowds as a form of entertainment and amusement with a narrator accompanied by actors or actress. Folktales which are known as "Anansesem" teaches a lot of moral lessons and attitudes accepted in a community. The narrators are usually elderly people who use the folktale as a tool for guiding and counselling the young ones in the society.

\section{Music}

Music in Ghana exists in three main forms or categories. The first type or category consists of music modeled on Western principles and they are played in the concert hall. The second category is what is termed popular music and is connected with dancing. Examples includes: Gabada,

Bכbככbכ, Gahu, Highlife, Reggae, etc

The third category is made up of music which is connected with Ghanaian traditional institutions and is therefore, performed mostly during traditional occasions like chieftaincy affairs, enstoolment or enskinment and destoolment or deskinment, organized communal labour, ceremonies of the life cycle events such as puberty, marriage and death as well as recreation and festivals. With regards to puberty rites the songs are not only songs of joy but also songs in which references are made to the duties and expectations of motherhood. Respondent 2 (R2) said the following when asked how music is used as a form of guidance to marriage couples: 
"It is true that music is used to send a lot of signals to people especially marriage couples. During marriage ceremonies, friends, loved ones and families come together to support the couples and bid them well in their marriage. During this time, music is usually played for all people presents to dance, socialise and know themselves well. Again, some of the music played or sang during the ceremony sends some advice and alertness to the couples. These music usually advise the couples on some of the benefits and challenges they will likely encounter in their journey of marriage. Moreover, during this same ceremony, 'don dooooo' (which means you don't know) is normally yelled out to the newly couples. This is to preinform the couples that there are a lot of experiences they are to encounter and for that matter, they should armed themselves well because these unseen experiences can make and unmake their marriage." (R2)

\section{Role of Traditional Guidance and Counselling}

Traditional guidance and counselling has played a vital role in the Akan settings. As indicated above, it comes in many forms to help inculcate discipline in the youth. Some of the major role traditional guidance and counselling portrays includes the following:

Traditional guidance and counselling is a form of imparting cultural values within the younger generation. Cultural values are principles and standards that cherished by a particular group of people. Every Akan society attach some form of importance to cultural values because they belief that when values are obeyed, it prevents disgrace and humiliation. "animguasemfataokaniiba" (Disgrace cannot be used for Akan child) is an adage that the Akans especially people of Sefwi Bekwai use to teach their young ones why they should cherish societal values. Some of the cultural values stipulate that, a girl or boy is supposed to be completely ignorant of sexual matters until he or she is physiological and socially mature (Sarpong, 1974). Respondent one (R1) said the following on cultural values:

\begin{abstract}
"In Sefwi Bekwai, cultural values are not documented but every parent or adult knows all these values. For these values, we expect the immediate families of the child to carry the primary burden of teaching the child the appropriate values. For instance, when there is a case of juvenile immorality, the parents are normally invited and at times fined or castigated severely. This is because, it is believed that they (parents) are the right people to direct and teach their children these common values and practices". (R1)
\end{abstract}

Another major role of traditional guidance and counselling is helping the youth to identify and accept their gender roles in life. As a growing person there are certain roles and duties that are expected from you. These roles are normally distributed by parents on the basis of gender. Whiles girls are limited to the kitchen, boys are usually allowed to explore nature for example, boys are allowed to go to school, do farming and mining etc. Traditional counsellors hold a belief that it is an abomination for boys to cook and girls to engage in physical work. One cannot neglect these roles without risking to be branded as uncouth, shameless or foolish (Sarpong, 1974). In relation to Sefwi-Bekwai, the assumption that girls are relegated to the kitchen and boys to explore the world has not gained full root. A respondent who is a teacher commented that even though most of the females are not schooling, a considerable number of them are in schools and are doing better.

Again, traditional guidance and counselling helps in the development of skills and potential of its members. Whiles some people can easily identify their skills and potentials, others find it difficult to do that. By the assistance of traditional guidance and counsellors, some people especially the youth are able to unearth and develop certain in built potentials. Traditional counsellors in Sefwi-Bekwai usually assist people to develop their skills in drumming, music, wood carving, weaving and mental work. This is what Respondent three (R4) said when asked to express his view on how he became a wood carver:
"When I was 12 years, I used to accompany my grandfather to his carpentry shop near the chief's palace. Whiles 'Oluman' (Oldman) will be working I will be chiselling unused woods. Later my grandfather realised I was carving some nice objects like toy cars and cups. So at age 16, I was sent to a wood carver as an apprentice. Within two years, I was able to carve almost everything I see. In fact through this carving I have been able to build my own house and send my children to school. Thanks to by grandfather who saw that great gift in me". (R4)

Situations that Precipitate the Offering of Traditional Guidance and Counselling

Through the personal interviews and observations in SefwiBekwai, it was evident that nothing ideally brings about guidance and counselling. It was obvious that they guide and counsel their wards right from infancy. However, there are certain occasions and ceremonies; one can see the administration of counselling at its highest form. Some of these occasions include marriage ceremonies, funeral, puberty, during unwanted pregnancies, travelling etc. Respondent 1 (R1) who is closer had this to say:
"Actual counselling is seen when a man or woman gets married. Here the couples are normally advised by families of both parties especially by the 'abusapanin' (Family Head). Couples are given some counsel that will help them sustain their marriage. Again, counselling is usually given when one loses his or her close partner or relative. We believe that, when counselling is not given it can even lead to another casualty. So what we do is that we normally send in 
an old person to stay with the person who has lost his relative for some days. The idea behind is to counsel the person and also prevents him or her from causing suicide. We also give counselling to our children when they are travelling to big cities like Accra and Kumasi. Most of us have not been there in our life time but we have heard what actually goes on there. So we advise our relatives very well before they embark on such trips. Another area I can remember we also give counselling is when a girl reaches her puberty. The girl is made to know what can happen to her when she engages in premarital sex". (RI)

Traditional Practitioners of Guidance and Counselling and Formal Training

In Akan political system there are series of hierarchical levels of authority which operates from the family units through the lineage until the final authority, the 'Omanhene' (the paramount chief). The important levels are the household, the compound, the lineage, the village, the divisional chiefs and the paramount chief (Nukunya 2003). It is clear that most of our traditional leaders are without formal education but rich in our local traditions and way of life. In the case of SefwiBekwai, even though some of the traditional counsellors are educated, most of them are without formal education yet they function effectively in delivering of counselling services. Most of them rely on experience and old age. These imply that traditional practitioners do not necessarily need formal education, but their knowledge in tradition and experience alone is enough to offer suitable counselling to the younger generation.

\section{Confidentiality in Traditional Guidance and Counselling}

Confidentiality is a key ingredient in the delivery of guidance and counselling services both professionally and unprofessionally. A counsellor disclosing his or her client's problem outside the public domain has flaunted the ethical issues in counselling. In the case of Sefwi-Bekwai where most of the counsellors have not received formal education, the issue of confidentiality in counselling has become a little headache. This is because there are times people complain their secrets have been diffused in the air which they believe they disclosed it to a traditional counsellor. Respondent 4 (R4) shared his plight on the area of confidentiality:

"I once remember I had a problem with my partner and I was advised to see one prominent man within our vicinity. I shared all my problems with him, and in fact he gave me a laudable solution which really helped to solve the confrontation I had with my partner. For about a week after my meeting with the man, I overheard a co tenant discussing the same issue I shared with that prominent man. In fact, I was shocked because it was one of my secrets, I did not want it to leak. Upon interrogation the old man, he apologised and told me it was just a mistake. I nearly had a squabble with him but I did not want the matter to attract more attention so I stopped arguing with him and left his house. It really hurt”. (R4)

However, there are some traditional counsellors who are very conscious and careful about the idea of confidentiality. Most believe that if someone does not trust you, the person would not pour his or her top secrets to you. It is therefore imperative to keep people secrets and problems they share with you.

What are the Pros and Cons of Traditional Guidance and Counselling?

Traditional Guidance and Counselling has played many roles and functions in the traditional settings of Ghana especially among the people of Sefwi-Bekwai however, some flaws have been associated with it. Below are some identified advantages and disadvantages associated with traditional Guidance and Counselling among the people of Sefwi-Bekwai in the Ashanti Region:

\section{Benefits}

Traditional Guidance and Counselling has promoted cultural values of the community as well as family values. Chiefs, parents, clans' heads, teachers and the elderly people in Sefwi-Bekwai have managed to inculcate in their young ones the rich cultural values and practices of the land.

Again, through guidance and counselling, indigenes have learnt to resolve disputes amongst themselves. Respondent 2 (R2) had this to say:

"Here, we hardly go to government court. The clan and family heads who serve as counsellors have trained us to live peacefully among ourselves. When strife and struggling erupt, we know how to deal with them peacefully". (R2)

Traditional counsellors, through their yeoman's services delivery have helped people to establish long lasting relationships which some have resulted into marriages.

Moreover, traditional guidance and counselling has helped preserve the culture, traditions, history and heritage of the people of Sefwi-Bekwai.

According to Munikwa et al (2012), traditional counselling methods have emphasized the importance of helping the individual, thus going against the influence of the family and community structures. Knowing when and how to integrate the family and community into counselling practice will empower culturally different clients and help them seek a collective solution rather than an individual one.

\section{Disadvantages}

Delivering traditional guidance and counselling services is somehow myopic. The traditional counsellors usually judge and counsel individuals based on their own personal experiences. Most of their personal experiences might not be applicable to all yet they feel younger ones should abide and take them wholeheartedly. Some of the advice they give 
usually are not in consistent with laws of the entire nation. For instance, in Sefwi-Bekwai, female teenagers are normally counsel not to mingle with the opposite sex when they experience menarche. This is contrary to the law of free association of all persons which is found in the constitution of the nation.

Also, in traditional guidance and counselling among the Sefwi-Bekwai, there are no proper theoretical underpinnings. Their counsellors do not rely on any documented theory or assumptions when discharging their counselling duties. They usually base their assumptions on hearsays, traditions and spiritual beliefs. All these assumptions may one way or the other lack some level of veracity.

\section{RECOMMENDATION}

From the findings, the following recommendations are proposed:

The role of traditional counsellors in communities should be acknowledged and made known to all persons.

Indigenes should be made aware of their counsellors whom they can approach for assistance whenever there is a problem.

This study also recommends that there should be training courses in counselling for traditional leaders. Such training can assist these counsellors to beef up their counselling services delivery. This will also ensure consistency in the way counselling is conducted traditionally. Furthermore, the study recommends that to maintain the African philosophy, the people need to go back to their roots to reclaim from their past practices what is wholesome and best, merge it with best western practices and use it to rebuild African guidance and counselling with modernity. This would enable them to render a more satisfying and effective assistance to their clients (Affum K. P, Kuranchie A. \& Mensah K. M. 2016).

Finally, it is recommended that, traditional counsellors can also come together to carry out general public outreach programmes on pertinent issues like relationships, cultural practices, career development, etc.

\section{CONCLUSION}

It is obvious that traditional guidance and counselling has existed long with the Ghanaian communities especially with the people of Sefwi-Bekwai and that modern contemporary guidance and counselling came to augment existing one. Due to its relevance, traditional guidance and counselling should be made accessible to all and sundry in our various communities so as to assist the younger generation have a sense of direction and purpose in life.

\section{REFERENCES}

[1] Achebe, C. C. (1988). Theories of Individual Counselling: Relevance to the Nigerian Situation. Five colleges Black Studies Press Amherst, Massachusetts.

[2] Affum, P. K., Kuranchie, A., \& Mensah, M. K. (2016). The place of theory in traditional guidance and counselling in modern Ghanaian cultures. African Educational Research Journal, 4(3): 131-139.

[3] Bedu-Addo, P.K.A. (2000). Guidance and Counselling 'unmasked'. (3rd Ed.). Accra. Type Company Limited.

[4] Egbochuku, E. O. (2008). Guidance and counselling: A comprehensive text. UNIBEN Press

[5] Hoitsbaum, H. P. (1925) "Sefwi and Its Peoples" The Gold Coast Review, 1, p.76-9^.

[6] Daaku, K. Y. (1970). Oral Traditions of Sefwi-Wiawso and Bekwai.

[7] Fortes M.\& Evans-Pritchard E.E. (1987). African Political Systems. KPI. Social Science.

[8] Keulder, C. 1997b. Traditional Authorities and Regional Councils in southern Na- mibia. Windhoek: Friedrich-Ebert-Stiftung.

[9] Logie P. (2009). A History of the Akan People. Published.

[10] Munikwa J, Mutopa S, Maphosa C (2012). The nature and causes of parasuicide cases handled by tradi- tional leaders in Hurungwe District in Zimbabwe. Journal of Human Ecology, 3(2): 93-102

[11] Nukunya G.K. (2003). Introduction to Sociology. University Press: Social Science

[12] Odebunmi,A (1992).Understanding Guidance and Counselling. Printed by Gbemi Sopipo Press LTD Abeokuta.

[13] People, James, Bailey, Garrick (2010). Humanity: an introduction to cultural Anthropology ( $9^{\text {th }}$ edition). Wadsworth Cengage learning. Page 389.

[14] Sarpong P. (1974) Ghana in Retrospect, Some Aspects of Ghanaian Culture. Ghana Publishing. Corporation (Printing Division) Accra - Tema.

[15] Stewart, J. M. (1966) Akan History: Some Linguistic Evidence, Ghana Notes and Queries, Accra: Historical Society.

[16] Tony and Pool (2013) African tradition: Victoria falls home page.

[17] World Health Organisation (2006). Preventing Suicide: A Resource Guide for Counsellors. WHO: Geneva. 